\title{
Shortage of Personal Protective Equipment and Nurse Safety in the Coronavirus Disease-19 Pandemic: A Cross-sectional Study in Indonesia
}

\author{
Sr Anita Sampe ${ }^{1 *}$, P. M. M. Sumarti Endah ${ }^{2}$, Mery Sambo $^{1}$, Siprianus Abdu ${ }^{1}$ \\ ${ }^{1}$ Department of Nursing, Stella College of Health Sciences, Makassar, Indonesia; ${ }^{2}$ Health Polytecnic Karya Husada Jogjakarta, \\ Yogyakarta, Indonesia
}

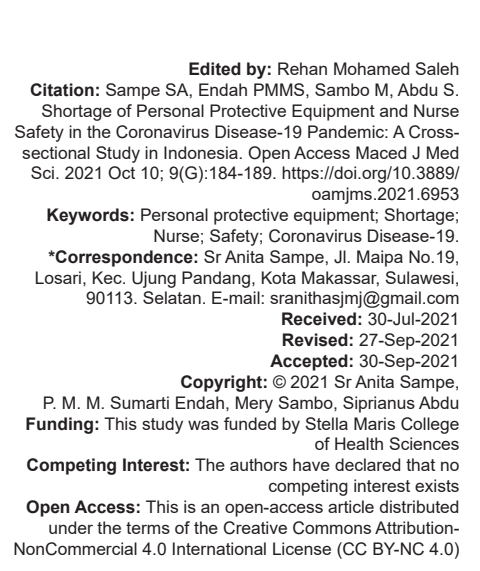

Introduction

The Coronavirus disease-19 (COVID-19) epidemic was declared a significant worldwide crisis by the World Health Organization [1]. About 115.056 cases have been recorded daily in Indonesia, with nearly 1000 recent cases and a 4.7 death rate, making Indonesia the second largest associated COVID-19 country in the Asia-Pacific area. The proportion of confirmed COVID-19 cases among nurses has risen to as high as $11 \%$ in some countries, with a growing number of occupationally attributable deaths being documented [2], [3]. Between February 12 and April 9, 2020 , it was announced that $19 \%$ of medical workers in the United States and $20 \%$ in Italy were infected with COVID-19 4. In Indonesia, the number of medical personnel who died of COVID-19 infection on July 12, 2020, was 61 doctors and 39 nurses. The risks posed by COVID-19 to nurses are substantial but mainly avoidable [4]. Many nurses were not allowed to return home (to remain with their families) due to close interaction with confirmed COVID-19.
Using personally protected equipment (PPE) is one effort to reduce virus transmission to hospital nurses. 5 According to the Directorate General of Health (2020), nurses' PPE must adhere to a riskbased standard. The standard for PPE includes gowns, gloves, N95 or surgical masks, headgear, eye protection (goggles), protective footwear (boots), and a face shield. The usage of PPE must conform with the protocols for putting on and taking off both disposable and reusable PPE. There seems to be little data to suggest which PPE provides the best prevention; nevertheless, education in wearing and doffing, simulation, and face-to-face directions are all likely to be advantageous [5]. Due to proper teaching, the accessibility of fitness tests, and distribution limitations [6], nurses cannot use PPE following the suggested recommendations [7].

There has been a substantial scarcity of PPE in several countries during the ongoing pandemic of COVID-19 201 [7], [8], [9]. It has posed a problem in delivering health-care services that can significantly avoid the possibility of being infected 
with COVID-19 [10]. In addition to the concern of accessibility, the PPE packages given should also contain formal application requirements. The simplicity of the process, thermal convenience and ventilation, and visibility, and long-term concerns such as cervical discomfort, backache, and unpleasant allergic reactions are all included [11], [12], [13]. Nurses' faces injured from prolonged use of helmets were utilized to show the severe working situations involved in caring for such patients. While discomfort, heat strain, and water losses were anticipated by scientific evidence utilizing Powered Air-Purified Respirators [13], PPE for the nurses does not provide real-life information.

Nurses in Indonesia also experience a shortage of PPE as the number of COVID-19 patients in Indonesia continues to increase. There is no accurate data yet regarding the exact number of PPE scarcity for nurses. However, the Secretary-General of the Pharmaceutical and Medical Devices Ministry of Health on April 14, 2020, estimates that Indonesia has a shortage of PPE of around 8 million units for the community and medical personnel. Although the government is trying to help distribute PPE to all corners of the country, the amount remains insufficient. This situation prompts the government and various elements of society to produce their PPE and open for donation. This study aimed to describe the availability of PPE and adverse consequences long-term used off the PPE and to examine the relationship between shortage PPE with nurse behavior response in Indonesia.

\section{Methods}

An online-based survey was used to collect nurse reports regarding $\mathrm{PPE}$ associated with the COVID-19 pandemic. This study was conducted in medical center, private hospital, general public hospital, emergency hospital, BUMN's hospital in only one province of Indonesia, namely, Yogyakarta. It is the capital city of Special Region of Yogyakarta in Indonesia, on the island of Java and the only Indonesian royal city still ruled by a monarchy.

\section{Sample}

All nurses who are directly involved in the management of COVID-19 patients were invited to participate in the survey. Participants were chosen using convenience sampling. G-Power Software version 3.1.6 is used to calculate you sample size with $\alpha=0.05$, effect size $=0.08$, and power level $=0.80$. In this study, a total of 211 questionnaires were gathered.

\section{Survey instrument}

A study-related survey was developed in two parts. The first section is regarding basic demographics, including age, gender, education level, and working unit. The second section included a series of questions about PPE availability and the negative impacts of PPE on the nurse. The survey began with a binary question: If a responder indicated that they were personally caring for COVID-19 patients, the questionnaire was completed, and the answer was classified as valid. In the alternative scenario, the questionnaire was canceled, and the answer was deemed invalid.

PPE availability was measured using a developed questionnaire by the researchers' teams. The questions were consisted of 15 items, with two options (yes [1] and [0]). The questionnaire on limited PPE provision has a validity score of $>0.349$ and a reliability score of 0.812 . We also measure about nurse perception toward PPE using a developed questionnaire by the researchers' teams. The questions were consisted of 15 items, with five options (strongly disagreed [1] to strongly agreed [5]). Insufficient perception was categorized if the score below the means value. The reliability score was 0.698. In addition, nurse behaviors toward PPE were measured using a developed questionnaire by the researchers' teams. The questions were consisted of 15 items, with five options (strongly disagreed [1] to strongly agreed [5]). Good behaviors were categorized if the score below the means value. The reliability score was 0.698 .

\section{Survey administration}

The survey was conducted using the Google form. The survey was scheduled to be open for 2 weeks beginning March 30 . An online survey (through a website application platform) was distributed to all charge nurses at both public and private hospitals. Participants might complete the questionnaire on a laptop or phone, which may result in the questionnaire opening a web-connected or checking a quick response code.

\section{Ethical consideration}

This study was approved by the affiliated institutions (727/KEPK/STIKES NHM/EC/XII/2020). Informed permission was gained through checkbox bo on the Google form.

\section{Data analysis}

Survey findings have been exported into SPSS version 23.00 and evaluated. This study employs univariate and bivariate analysis. The univariate analysis uses frequency distribution tables to explain all 
variables. The bivariate analysis used the Chi-square test to describe the relationship between two variables. $p<0.05$ was considered to be statistically significant.

\section{Results}

The characteristics of the 211 respondents are shown in Table 1, with the majority of respondents being female $(57.8 \%)$, in their early adulthood (43.6\%), pursuing graduate-level education (45.5\%), working in hospitals $(44.1 \%)$, working in general $(78.7 \%)$, and lived in urban are (58.73\%).

Table 1: Characteristics of respondent $(n=211)$

\begin{tabular}{lll}
\hline Variable & $\mathrm{n}$ & $\%$ \\
\hline Gender & 122 & \\
Female & 89 & 57.8 \\
Men & 19 & 42.2 \\
Age & 92 & 9.0 \\
Late adolescence & 79 & 43.6 \\
Early Adult & 21 & 37.4 \\
Late Adult & 19 & 10.0 \\
Early Elderly & & 9.0 \\
Education & 82 & 38.9 \\
Diploma & 19 & 9.0 \\
Graduate & 96 & 45.5 \\
Graduate Nurse & 14 & 6.6 \\
Postgraduate & & \\
Workplace & 16 & 7.6 \\
Medical center & 56 & 44.1 \\
Private Hospital & 93 & 0.9 \\
RSUD & 2 & 0.5 \\
Emergency Hospital & 1 & 20.4 \\
BUMN's Hospital & 43 & 41.27 \\
Central hospital & & 58.73 \\
Resident area & 87 & \\
Rural area of Yogyakarta & 124 & \\
Urban area of Yogyakarta & &
\end{tabular}

The majority of the mask $\mathrm{N} 95$ provision reaches up to $80 \%$. The second is the hazmat $(71 \%)$ and the lowest in the gloves (30\%) (Figure 1). Around $71 \%$ of respondents generally resist removing their PPE until the shift is complete. Then $62 \%$ of the respondents are ready to propose to the leaders of the PPE, and $51 \%$ indicate that they are modifying the PPE but still according to the required standard, and just $5 \%$ state that they are not working if the PPE is not available (Figure 2).

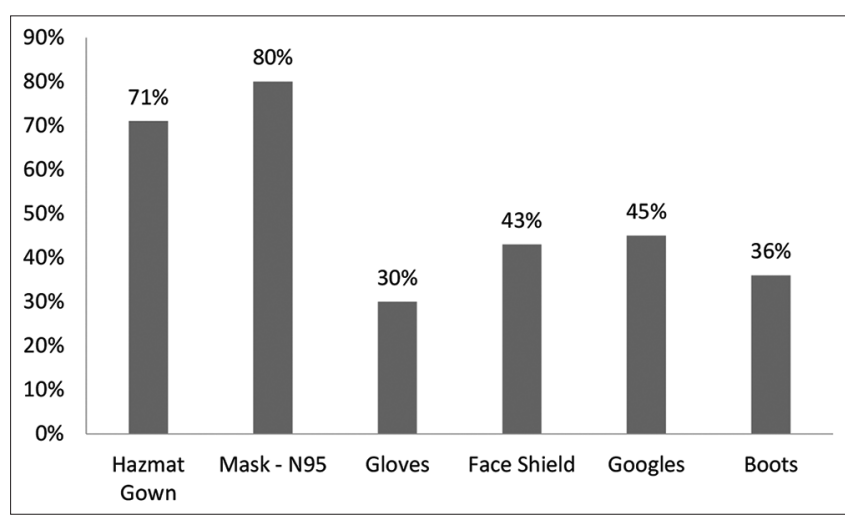

Figure 1: Provision of personal protective equipment in Coronavirus disease-19 services

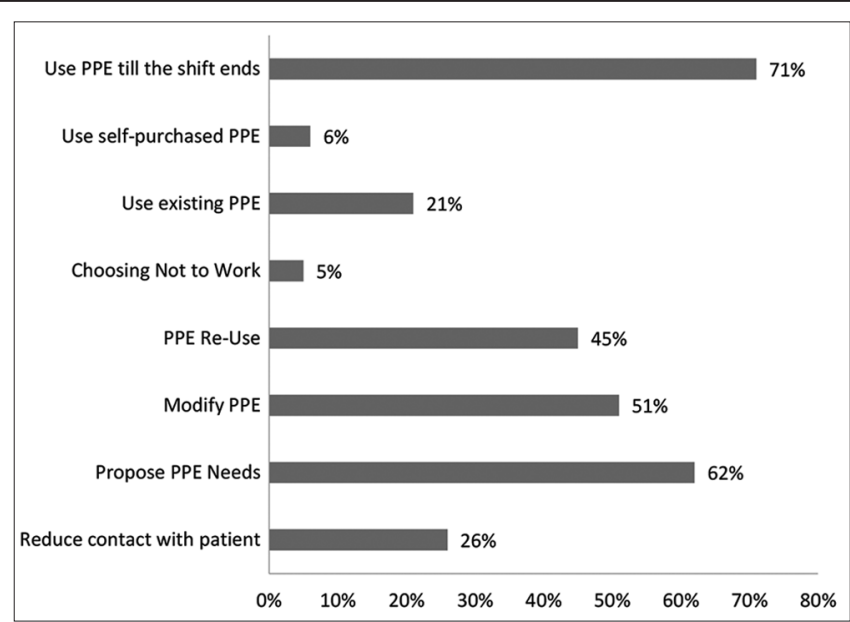

Figure 2: Nurse action during a shortage of personal protective equipment supplies

Figure 3 shows the types of injuries and discomforts caused by prolonged PPE use. Nasal blisters are the most prevalent type of injury sustained by nurses while wearing PPE (86\%). Headaches and dehydration are the most common side effects of prolonged PPE use (Figure 3).

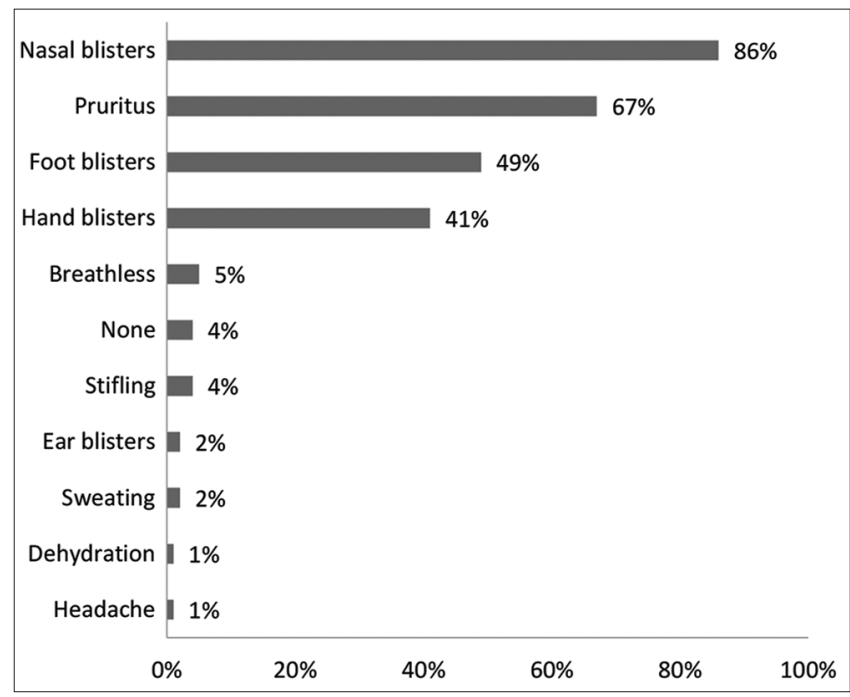

Figure 3: Problems experienced injury due to the use of personal protective equipment

Table 2 depicts the association between PPE shortage and nurse behavior in dealing with PPE shortage. This study found that most respondents (60.7\%) with insufficient PPE had a positive behavior reaction, whereas just $18 \%$ had a poor behavior reaction. The bivariate analysis found the relationship between PPE shortage and nurse behavior $(p=0.044)$.

Table 2: The relationship between PPE shortage and nurse's behavior in addressing the lack of PPE Provision

\begin{tabular}{|c|c|c|c|c|c|c|c|c|}
\hline \multirow{3}{*}{ PIPE } & \multicolumn{4}{|c|}{ Nurse behavior } & \multirow{2}{*}{\multicolumn{2}{|c|}{ Total }} & \multirow[t]{3}{*}{$\overline{X^{2}}$} & \multirow[t]{3}{*}{$p$-value } \\
\hline & \multicolumn{2}{|c|}{ Good } & \multicolumn{2}{|c|}{ Poor } & & & & \\
\hline & $\mathrm{n}$ & $\%$ & $\mathrm{n}$ & $\%$ & $n$ & $\%$ & & \\
\hline Sufficient & 28 & 13.3 & 17 & 8.1 & 45 & 21.3 & 8.092 & 0.044 \\
\hline Insufficient & 128 & 60.7 & 38 & 18 & 166 & 78.7 & & \\
\hline
\end{tabular}




\section{Discussion}

Almost all nurses reported a lack of PPE, although the number of COVID-19 patients in Indonesia continues to rise. The PPE crisis affects numerous countries worldwide [5]. According to the WHO, the shortage of PPE is caused by rising demand, panic buying, hoarding, and abuse of PPE. [6] Furthermore, many nurses have difficulties obtaining N95, which is like a recent study in which medical masks and $71 \%$ of clothing or hazmat are limited [6]. Delgado et al. (2020) revealed that medical staff in Latin America had only $67.3 \%$ access to gowns/hazmat, $56.1 \%$ to N95 masks, and $32.6 \%$ to face protection equipment. Medical staff is at a greater risk of becoming contaminated when treating patients due to a lack of PPE supplies.

About $62 \%$ of respondents recommend to national government leaders the best solution to alleviate PPE scarcity. The hospital administration should always communicate with all staff; give transparent information on an accurate picture of what is to come, such as PPE shortage and medical equipment [13]. In addition, the leader should encourage enthusiasm and faith in medical professionals and provide an opportunity for medical personnel to research one of the solutions to this pandemic outbreak. In this survey, almost half of respondents recycled PPE and modified it to meet standards. Some nurses even designed their PPE. Many governments and organizations in North America and Europe have developed their protective equipment. Ireland has even established a national Production Planning-Body for PPE, which has effectively manufactured CPAP helmets, arthroplasty helmets, and ventilators [12], [14]. The central government used the same approach, which has encouraged people to construct their protective equipment (PPE) and increase awareness of the PPE standard and guidelines for utilizing PPE, such as cloth masks, gowns, and gown and face shields. Although it is impossible to produce disposable PPE such as N95 masks or goggles on one's own, specific tools such as coveralls, aprons, surgical hoods, and (cloth) masks can be re-used after decontamination. Recycling of PPE is permitted if the amount of PPE is limited. 17 Some countries have even developed lowcost and highly effective decontamination techniques that allow workers to re-use their PPE [12], [15].

The majority of respondents in this study opted to delay putting on PPE until the shift was complete. This finding is consistent with previous research indicating that nurses wear PPE until they return home due to a limited supply of PPE [11]. The health association recommends extending the usage of PEP to eliminate shortcomings. It can be done if the PPE is still in good condition, clean, and not contaminated with infectious fluid from the patient. Limiting interaction with patients is another efficient method of reducing PPE usage. The World Health Organization suggests adopting telemedicine to analyze suspected COVID19 cases, using glass or plastic partitions in the triage area, registration tables in emergency departments and pharmacies, restricting patient visitation, and minimizing bundling care activities. It is also recommended to postpone all elective operations, endoscopic lists, and clinics to avoid transmission [3].

Long-term usage of tight-fitting, doublecoated PPE might cause damage. A few of the injuries reported by the responders are nasal and ear blisters, itching, perspiration, overheating, and headache. Similar to the previous study, many medical workers suffered nasal injuries and blisters on their hands and feet due to the usage of PPE during providing Covid-19 care and treatment [16]. PPE also impairs nurses' dexterity while performing their duties; multiple layers of gloves create discomfort; flexible face shields cause sight abnormalities; some nurses complain of back pain, cold, and dehydration [17]. Even though PPE used in industries is constructed of a variety of materials, skin problems produced by PPE used on the same portion of the body have a similar effect [17], [18]. Comprehensive preventative actions, such as enhancing PPE and reducing usage duration, will keep nurses safe [16].

The use of PPE is one of many strategies for reducing infection transmission in hospitals. Since all health facilities require PPE, supplies are scarce, and it is not easy to obtain. The research showed that the respondents were well-behaving concerning the restrictions on PPE access. There is a relationship between the availability of PPE and nurse behavior response. It is similar to the previous research, in which medical staff responded positively when they were unable to access PPE [19]. It should be highlighted that nurses respond favorably to this approach because there is no more effective or efficient method of providing PPE than changing and recycling it. The report can be used as a reference for determining how and when this PPE is applied, especially when it has to be decided or when there is strong demand for the usage of the PPE.

This study has certain limitations that should be acknowledged. First, a voluntary survey and answers represent views and perspectives only. This study was only conducted in one province of Indonesia, which is Indonesia has 35 provinces; thus, generalizability may limited to the specific context on this study. However, this province included in metropolitan city which consist of many Indonesian nurses' representative to all nurses in Indonesia. They may not always represent actual procedures, as this is not audited. Second, instead of using a systematic 
sample approach, we created the survey readily accessible. Therefore, there is no denominator to compute a rate of response. As a result, our findings may only represent a small part of the actual thoughts of all nurses, and they may be biased.

\section{Conclusion}

The majority of nurses have difficulties accessing N95, and nurses' response to the most severe PPE restrictions is to refrain from putting off PPE until the time shift begins. Nasal blisters are the most common PPE-related injury among nurses. Although the supply of PPE is limited, nurses demonstrate appropriate behavior in this situation. Protecting the PPE supply chain will ensure the continuation of critical healthcare services and contribute to reducing mortality. Policymakers should take urgent action to tackle these concerns. Future study could explore in others province regarding nurse behaviors toward PPE as PPE is an important protect of COVID-19 during their professional practices.

\section{Acknowledgments}

I would like to thank all participants of the study and my entire colleagues who have encouraged us to complete this paper.

\section{References}

1. Li Q, Guan X, Wu P, Wang X, Zhou L, Tong Y, et al. Early transmission dynamics in Wuhan, China, of novel coronavirusinfected pneumonia. N Engl J Med. 2020;382(13):1199-1207. http://doi.org/10.1056/NEJMoa2001316 PMid:31995857

2. Wang J, Zhou M, Liu F. Reasons for healthcare workers becoming infected with novel coronavirus disease 2019 (COVID-19) in China. J Hosp Infect. 2020;105(1):100-1. http:// doi.org/10.1016/j.jhin.2020.03.002

PMid:32147406

3. Herron JB, Hay-David AG, Gilliam AD, Brennan PA. Personal protective equipment and Covid 19- a risk to healthcare staff? Br J Oral Maxillofac Surg. 2020;58(5):500-2. http://doi. org/10.1016/j.bjoms.2020.04.015

PMid:32307130

4. Ong JJ, et al. Headaches associated with personal protective equipment a cross-sectional study among frontline healthcare workers during COVID-19. Headache. 2020;60(5):864-77. http://doi.org/10.1111/head.13811

PMid:32232837
5. Bauchner H, Fontanarosa PB, Livingston EH. Conserving supply of personal protective equipment-a call for ideas. JAMA. 2020;323(19):1911. http://doi.org/10.1001/jama.2020.4770 PMid:32196543

6. Phua J, Weng L, Ling L, Egi M, Lim CM, Divatia JV, et al. Intensive care management of coronavirus disease 2019 (COVID-19): Challenges and recommendations. Lancet Respir Med. 2020;8(5):506-17. http://doi.org/10.1016/ S2213-2600(20)30161-2

PMid:32272080

7. Bartoszko JJ, Farooqi MA, Alhazzani W, Loeb M. Medical masks vs N95 respirators for preventing COVID-19 in healthcare workers: A systematic review and meta-analysis of randomized trials. Influenza Other Respir Viruses. 2020;14(4):365-73. http:// doi.org/10.1111/irv. 12745

PMid:32246890

8. Delgado D, Quintana FW, Perez G, Liprandi AS, PonteNegretti C, Mendoza I, et al. Personal safety during the COVID-19 pandemic: Realities and perspectives of healthcare workers in latin America. Int $\mathrm{J}$ Environ Res Public Health. 2020;17(8):2798. http://doi.org/10.3390/ijerph17082798 PMid:32325718

9. Ng K, Poon BH, Puar TH, Quah JL, Loh WJ, Wong YJ, et al COVID-19 and the risk to health care workers: A case report. Ann Intern Med. 2020;172(11):766-67. http://doi.org/10.7326/ L20-0175

PMid:32176257

10. Sugiyono. Sugiyono, Metode Penelitian Kuantitatif Kualitatif dan $\mathrm{RI}$ and D. CV Alf Bandung; 2008.

11. Hirschmann MT, Hart A, Henckel J, Sadoghi P, Seil R, Mouton C COVID-19 coronavirus: Recommended personal protective equipment for the orthopaedic and trauma surgeon. Knee Surg Sports Traumatol Arthrosc. 2020;28(6):1690-8. http://doi. org/10.1007/s00167-020-06022-4

PMid:32342138

12. Rowan NJ, Laffey JG. Challenges and solutions for addressing critical shortage of supply chain for personal and protective equipment (PPE) arising from Coronavirus disease (COVID19) pandemic--Case study from the Republic of Ireland. Sci Total Environ. 2020;725:138532. http://doi.org/10.1016/j. scitotenv.2020.138532

PMid:32304970

13. Garg M, Wray CM. Hospital medicine management in the time of COVID-19: Preparing for a sprint and a Marathon. J Hosp Med. 2020;15(5):305-7. http://doi.org/10.12788/jhm.3427

PMid:32379037

14. Erickson MM, Richardson ES, Hernandez NM, Bobbert DW $2^{\text {nd }}$ Gall K, Fearis P. Helmet modification to PPE with 3D printing during the COVID-19 pandemic at Duke University medical center: A novel technique. J Arthroplasty. 2020;35(7S):S23-7. http://doi.org/10.1016/j.arth.2020.04.035 PMid:32354536

15. Weaver DT, McElvany BD, Gopalakrishnan V, Card KJ, Crozier D, Dhawan $\mathrm{A}$, et al. UV decontamination of personal protective equipment with idle laboratory biosafety cabinets during the COVID-19 pandemic. PLoS One. 2021;16(7):e0241734. http:// doi.org/10.1101/2020.03.25.20043489 PMid:34310599

16. Jiang $Q$, Liu $Y$, Wei $W$, Zhu $D$, Chen $A$, Liu $H$, et al. The prevalence, characteristics, and related factors of pressure injury in medical staff wearing personal protective equipment against COVID-19 in China: A multicentre cross-sectional survey. Int Wound J. 2020;17(5):1300-9. http://doi.org/10.1111/ iwj.13391

PMid:32396265 
17. Loibner M, Hagauer S, Schwantzer G, Berghold A, Zatloukal K. Limiting factors for wearing personal protective equipment (PPE) in a health care environment evaluated in a randomised study. PLoS One. 2019;14(1):e0210775. http://doi.org/10.1371/ journal.pone.0210775

\section{PMid:30668567}

18. Singh M, Pawar M, Bothra A, Maheshwari A, Dubey V, Tiwari A, et al. Personal protective equipment induced facial dermatoses in healthcare workers managing Coronavirus disease 2019.
J European Acad Dermatol Venereol. 2020;34(8):e378-80. http://doi.org/10.1111/jdv.16628

PMid:32396675

19. Stewart CL, Thornblade LW, Diamond DJ, Fong Y, Melstrom LG. Personal protective equipment and COVID-19: A review for surgeons. Ann Surg. 2020;272(2):e132-8. http://doi. org/10.1097/SLA.0000000000003991

PMid:32675516 